\title{
Pengaruh Berat Roller Terhadap Performa Mesin Yamaha Mio Soul 110 Ce Yang Menggunakan Jenis Transmisi Otomatis (CVT)
}

\author{
Yos Nofendri $^{1 *}$, Evan Christian $^{2}$ \\ ${ }^{1,2}$ Teknik Mesin, Universitas 17 Agustus 1945 Jakarta \\ Yosnofendri@gmail.com \\ *Corresponding author - Email : Yosnofendri@gmail.com
}

Artkel Info - : Received : 17 Feb 2020; Revised : 26 Feb 2020; Accepted : 28 Feb 2020

\begin{abstract}
Abstrak
Dunia otomotif yang semakin berkembang menuntut perubahan agar alat transportasi lebih baik, tidak hanya pada mesinnya yang irit bahan bakar melainkan juga pada tingkat kenyamanan dalam berkendaraan. Salah satunya adalah perubahan pada sistem transmisi. Tujuan dari penelitian Tugas Akhir ini adalah untuk mengetahui prinsip kerja dan pengaruh variasi berat roller CVT (Continuously Varible Transmission) terhadap sepeda motor Yamaha Mio Soul 110 cc.Proses penelitian ini menggunakan metode eksperimental. Penelitian ini melakukan pengujian variasi berat roller menggunakan ukuran 7 gram , 10,5 gram dan 13 gram. Setelah dilakukan penggantian roller diharapkan dapat meningkatkan kinerja dari motor bakar 4 langkah. Metode penelitian yang digunakan adalah metode eksperimen yaitu dengan menahan throttle pada $3000 \mathrm{rpm}$, setelah stabil kemudian throttle diputar secara perlahan dengan interval 1000 rpm hingga 7000 rpm.Dari hasil analisis pengukuran untuk hasil pengujian variasi roller, jika menggunakan roller yang beratnya 13 gram maka meningkatkan prestasi mesin yaitu torsi 3,2 (Nm) dan mendapatkan daya yang maksimal sebesar 2,34 ( $\mathrm{kW}$ ) pada putaran mesin $7000 \mathrm{rpm}$, bahan bakar spesifik terbilang irit hanya 0,772 ( $\mathrm{kg} / \mathrm{kWh})$ dan efisiensi thermal 10,41 (\%). Hal ini terjadi karena berat roller mempengaruhi gaya sentrifugal pada pulley primer sehingga semakin berat roller maka mesin pada putaran tinggi, akan semakin kuat menjepit sabuk $V$ belt. sehingga pada putaran tinggi untuk mentransfer torsi dan daya ke roda belakang lebih besar.
\end{abstract}

Kata kunci: Performa, Transmisi, CVT, Variasi Roller

\begin{abstract}
The growing automotive world is demanding changes so that transportation is better, not only in the fuelefficient engine but also in the level of comfort in driving. One of them is a change in the transmission system. The purpose of this final project research is to determine the working principle and the effect of variations in the weight of the CVT (Continuously Variable Transmission) roller on the 110cc Yamaha Mio Soul motorcycle.This research process uses an experimental method. This study tested the variation of roller weight using a size of 7 grams, 10.5 grams and 13 grams. After changing the roller, it is expected to improve the performance of the 4 stroke combustion motor. The research method used is an experimental method by holding the throttle at $3000 \mathrm{rpm}$, after it is stable then the throttle is rotated slowly at intervals of $1000 \mathrm{rpm}$ to $7000 \mathrm{rpm}$.From the results of measurement analysis for the results of roller variation testing, if using a roller that weighs 13 grams increases engine performance ie torque of $3.2(\mathrm{Nm})$ and gets maximum power of $2.34(\mathrm{~kW})$ at $7000 \mathrm{rpm}$ engine speed, specific fuel relatively economical only $0.772(\mathrm{~kg} / \mathrm{kWh})$ and thermal efficiency $10.41(\%)$. This happens because the weight of the roller affects the centrifugal force on the primary pulley so that the heavier the roller, the machine at high speed, the stronger the $V$ belt belt will be clamped. so at high speed to transfer greater torque and power to the rear wheels
\end{abstract}

Keywords: Performance, Transmission, CVT, Roller Variations. 


\section{PENDAHULUAN}

Perkembangan sepeda motor dalam dunia otomotif semakin pesat dan didukung oleh teknologi yang modern. Agar lebih memudahkan pengendara dalam mengendarainya, diantaranya adalah sepeda motor dengan transmisi otomatis CVT (Continuously Varible Transmission). Kelebihan transmisi otomatis CVT (Continuously Varible Transmission) yaitu tanpa harus menaikan gigi dan sangat praktis dalam keadaan yang macet karena cukup memainkan thortle gas saja untuk menambah atau menurunkan kecepatan mesin tanpa harus menaikan gigi.

Penaikan acceleration pada motor yang bertransmisi otomatis terletak pada bagian CVT (Continuously Varible Transmission). Komponen yang terpenting didalam CVT (Continuously Varible Transmission) yaitu pulley primer dan pulley sekunder yang menghasilkan gaya sentrifugal untuk menekan kanvas ganda ke rumah kopling yang menghasilkan output daya untuk memutar as roda belakang.

Roller merupakan salah satu komponen yang terdapat pada transmisi otomatis atau CVT (Continuously Varible Transmission). semakin berat rollernya maka dia akan semakin cepat bergerak mendorong movable drive face pada drive pulley sehingga bisa menekan belt ke posisi terkecil, namun supaya belt dapat tertekan hingga maksimal butuh roller yang beratnya sesuai. Artinya jika roller terlalu ringan maka tidak dapat menekan belt hingga maksimal, efeknya tenaga tengah dan atas akan berkurang. Harus diperhatikan juga jika akan mengganti roller yang lebih berat harus memperhatikan torsi mesin".

M.Yamin dan Achmad Ardhiko (2011) juga menyatakan hal serupa "semakin ringan rollernya maka dia akan semakin cepat bergerak mendorong movable drive face dan face comp pada drive pulley sehingga bias menekan belt ke posisi terkecil. Efek yang terasa, aselerasi makin responsif, namun supaya $\mathrm{v}$-belt dapat tertekan hingga maksimal butuh roller yang beratnya sesuai juga. Artinya jika roller terlalu ringan maka tidak dapat menekan belt hingga maksimal. Efeknya tenaga tengah dan atas akan berkurang bahkan hilang". Penelitian ini akan melihat perbedaan prestasi mesin kendaraan bermotor yang menggunkan berat roler yang berbeda.

\section{TINJAUAN PUSTAKA}

\subsection{CVT (Continously Variable Transmission) Motor Matic.}

Ari Subagia dan Adi Atmika (2009) mengatakan sistem transmisi otomatis ini banyak digunakan pada sepeda motor jenis scooter dan dikenal dengan nama CVT (continously variable transmission) yang merupakan sistem transmisi baru tanpa gigi. Bentuk dan konstruksi dari sistem transmisi kendaraan ini sangat kompak dan sederhana dibandingkan dengan sistem transmisi lainnya. Jalius Jama (2009) juga mengatakan Transmisi otomatis umumnya digunakan pada sepeda motor jenis scooter (skuter). Transmisi yang digunakan yaitu transmisi otomatis "V" belt atau yang dikenal dengan CVT. CVT merupakan transmisi otomatis yang menggunakan sabuk untuk memperoleh perbandingan gigi yang bervariasi.

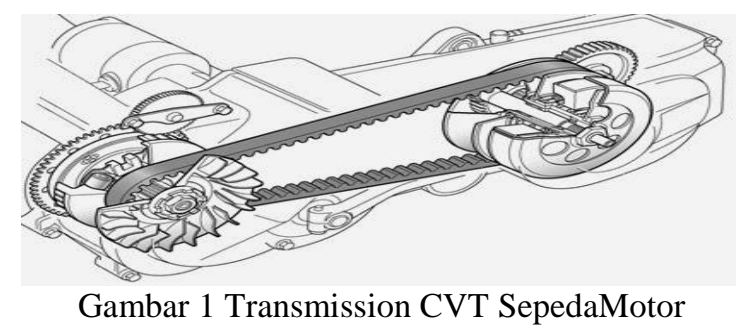

\subsection{Tranmisi}

Prinsip dasar transmisi adalah bagaimana bisa digunakan untuk merubah kecepatan putaran suatu poros menjadi kecepatan yang diinginkan untuk tujuan tertentu. 
Gigi transmisi berfungsi untuk mengatur tingkat kecepatan dan momen (tenaga putaran) mesin sesuai dengan kondisi yang dialami sepeda motor. Transmisi pada sepeda motor terbagi menjadi transmisi manual dan transmisi otomatis.

\subsubsection{Transmisi Manual}

Menurut Julius Jama (2008) komponen utama dari gigi transmisi pada sepeda motor terdiri dari susunan gigi-gigi yang berpasangan yang berbentuk dan menghasilkan perbandingan gigi-gigi tersebut terpasang. Salah satu pasangan gigi tersebut berada pada poros utama (main shaft/input shaft) dan pasangan gigi lainnya berada pada poros luar (output shaft/ counter shaft).

\subsubsection{Transmisi Otomatis}

Menurut Julius Jama (2008 : 335) Transmisi otomatis umumnya digunakan pada sepeda motor jenis scooter (skuter). Transmisi yang digunakan yaitu transmisi otomatis "V" belt atau yang dikenal dengan CVT (Continuously Variable Transmission). CVT (Continuously Varible Transmission) merupakan transmisi otomatis yang menggunakan sabuk untuk memperoleh perbandingan gigi yang bervariasi. Adapun komponen utama CVT (Continuously Varible Transmission) yaitu sebagai berikut:

- Puli Penggerak/ puli primer ( Drive Pulley/ Primary Pulley ).

- Puli yang digerakkan/ puli skunder ( Driven Pulley/ Secondary Pulley)

\subsection{Roller}

Roller merupakan salah satu komponen yang terdapat pada transmisi otomatis atau CVT. Roller adalah suatu material yang tersusun dengan teflon sebagai permukaan luarnya dan tembaga atau alumunium sebagai lapisan dalamnya. Roller berbentuk seperti bangun ruang yaitu silinder yang mempunyai diameter dan berat tertentu. Roller barfungsi untuk menekan dinding dalam puli primer sewaktu terjadi putaran tinggi. Prinsip kerja roller, hampir sama dengan plat penekan pada kopling sentrifugal. Ketika putaran mesin naik, roller akan terlempar ke arah luar dan mendorong bagian puli yang bisa bergeser mendekati puli yang diam, sehingga celah pulinya akan menyempit (Jalius Jama : 2008 : 337). Roller bekerja akibat adanya putaran yang tinggi dan adanya gaya sentrifugal (Mohamad Yamin : 2011).

Di dalam Lamtio fratomo (2013) "Prinsip kerja roller adalah semakin berat rollernya maka dia akan semakin cepat bergerak mendorong movable drive face pada drive pulley sehingga bisa menekan belt ke posisi terkecil, namun supaya belt dapat tertekan hingga maksimal butuh roller yang beratnya sesuai. Artinya jika roller terlalu ringan maka tidak dapat menekan belt hingga maksimal, efeknya tenaga tengah dan atas akan berkurang. Harus diperhatikan juga jika akan mengganti roller yang lebih berat harus memperhatikan torsi mesin".

M.Yamin dan Achmad Ardhiko (2011) juga menyatakan hal serupa "semakin ringan rollernya maka dia akan semakin cepat bergerak mendorong movable drive face dan face comp pada drive pulley sehingga bias menekan belt ke posisi terkecil. Efek yang terasa, aselerasi makin responsif, namun supaya v-belt dapat tertekan hingga maksimal butuh roller yang beratnya sesuai juga. Artinya jika roller terlalu ringan maka tidak dapat menekan belt hingga maksimal. Efeknya tenaga tengah dan atas akan berkurang bahkan hilang".

\subsection{Uji Prestasi Mesin}

Tujuan dalam menganalisa uji prestasi mesin adalah untuk memperbaiki power output dan ketangguhan dari mesin sehingga biaya yang dikeluarkan dapat 
diminimalisir sebaik mungkin. Dalam memperoleh prestasi motor bensin terhadap unjuk kerja mesin maka harus dilakukan pengujian dengan empat metode penelitian sebagai berikut:

\subsubsection{Torsi}

Torsi atau momen puntir adalah suatu ukuran kemampuan motor untuk menghasilkan kerja (Wiratmaja, 2010:20). Hal tersebut diperjelas oleh Raharjo dan Karnowo (2008:98) yang menjelaskan bahwa torsi merupakan ukuran kemampuan mesin untuk melakukan kerja jadi, torsi merupakan suatu energi. Besar torsi adalah besaran turunan yang biasa digunakan untuk menghitung energi yang dihasilkan dari benda yang berputar pada porosnya. Piston bergerak menghasilkan gaya $\mathrm{F}$ yang memutar poros engkol dimana panjang engkol sebesar $b$, sehingga torsi dapat ditentukan dengan rumus:

$\mathrm{T}=\mathrm{F} \times \mathrm{b}(\mathrm{N} \cdot \mathrm{m})$

$\mathrm{T}=$ torsi benda berputar (N.m).

$\mathrm{F}$ = gaya radial dari benda yang berputar $(\mathrm{N})$.

$\mathrm{b}=$ jari-jari engkol $(\mathrm{m})$.

\subsubsection{Daya Mesin}

Wiratmaja (2010:20) mendifinisikan daya sebagai hasil dari kerja, atau dengan kata lain daya merupakan kerja atau energi yang dihasilkan mesin per satuan waktu mesin itu sedang beroperasi. Daya yang dihasilkan pada proses pembakaran biasanya disebut daya indikator. Daya tersebut kemudian diteruskan pada torak yang bekerja bolak-balik di dalam silinder mesin. Di dalam silinder mesin terjadi perubahan energi dari energi kimia bahan bakar dengan proses pembakaran menjadi energi mekanik pada torak (Raharjo dan Karnowo, 2008:99). Menghitung besar daya pada motor empat langkah digunakan rumus sebagai berikut:
$\mathrm{P}=2 . \pi \cdot n \cdot \mathrm{T}(\mathrm{kW})$

Dimana:

$\mathrm{P}=$ Daya $(\mathrm{kW})$.

$\mathrm{n}=$ Putaran mesin (rpm).

$\mathrm{T}=$ Torsi mesin $(\mathrm{Nm})$.

\subsubsection{Konsumsi Bahan Bakar}

Besar penggunaan bahan bakar spesifik (SFC) ditentukan dalam $\mathrm{kg} / \mathrm{kwh}$ dan lebih umum digunakan dari pada $\eta b t$. Besar nilai SFC adalah kebalikan dari pada $\eta b t$. Penggunaan bahan bakar dalam gram per jam $\mathrm{Ne}$ dapat ditentukan dengan persamaan sebagai berikut:

$m_{f}=\frac{\rho \cdot v}{t}$

Dimana :

$\rho=$ Densitas Bahan Bakar $(\mathrm{kg} / \mathrm{dm} 3)$

$\mathrm{v}=$ Volume Bahan Bakar (ml)

$\mathrm{t}=$ Waktu (detik)

$\mathrm{mf}=$ Untuk penggunaan bahan bakar per jam pada kondisi tertentu $(\mathrm{kg} / \mathrm{jam})$

$S f c=\frac{m_{f}}{P}$

Dimana :

SFC = Konsumsi bahan bakar spesifik $(\mathrm{kg} / \mathrm{kWh})$

$\mathrm{P}=$ Daya mesin $(\mathrm{kW})$

Mf = Untuk penggunaan bahan bakar per jam pada kondisi tertentu $(\mathrm{kg} / \mathrm{h})$

\subsubsection{Efisiensi Thermal}

Efisiensi thermal efektif merupakan perbandingan antara kalor yang dirubah menjadi daya efektif dengan kalor yang dihasilkan dari pembakaran bahan bakar. Efisiensi termal efektif merupakan suatu ukuran untuk mengetahui ekonomis atau tidaknya dalam pemakaian bahan bakar, karena nilai dari efisiensi thermal efektif berbanding terbalik dengan nilai konsumsi bahan bakar spesifik. Jadi jika konsumsi bahan bakar spesifik efektif semakin turun, 
maka efisiensi thermal efektif akan meningkat. Besarnya efisiensi thermal efektif dapat dihitung dengan rumus:

$\eta_{t h}=\frac{P}{Q_{\text {in }}}$

Dimana:

$\mathrm{P} \quad=$ daya efektif $(\mathrm{kW})$

Qin = kalor sebenarnya bahan bakar $(\mathrm{kW} / \mathrm{s})$

Qin $=$ mf.LHV

Dimana :

$\mathrm{mf} \quad=$ Konsumsi bahan bakar $(\mathrm{kg} / \mathrm{h})$

LHV = Low heating value bahan bakar $(\mathrm{kJ} / \mathrm{kg})$

\section{METODOLOGI PENELITIAN}

Penelitian ini menggunakan metode ekperimental. Kendaraan bermotor yang digunakan adalah Yamaha Mio Soul 110 Cc Yang Menggunakan Jenis Transmisi Otomatis (CVT). Roler yang digunakan adalah memiliki berat 7 gram, 10,5 gram, dan 13 gram. Untuk ukuran standar pabrikan, roler yang digunakan adalah roler dengan berat 10.5 gram.

Penelitian yang dimulai dengan kajian literatur, pengambilan data dengan perbedaan berat roler pada tranmisi CVT. Pengambilan data dimulai pemasangan 1 unit sepeda motor pada alat dynotest dengan tujuan mendapatkan besar nya torsi yang dihasilkan oleh putaran mesin yang diteruskan ke roda belakang. Pengambilan data torsi dimulai dari putaran mesin 3000 Rpm - 7000 Rpm dengan inverval 1000 Rpm. Selain torsi, pengujian mesin juga menentukan banyak nya waktu (detik) untuk menhabiskan $15 \mathrm{ml}$ volume bahan bakar bensin.

Dalam penulisan ini tidak membahas secara mendalam mengenai kontruksi pada CVT (Continuously Varible Transmission). Mesin yang digunakan pada penelitian ini adalah sepeda motor Yamaha Mio Soul 110 cc. Penulis dalam kesempatan ini membahas tentang prinsip kerja serta memanipulasi berat roller untuk menaikan acceleration, torsi, daya dan pengaruh terhadap pemakaian bahan bakar spesifik.

\section{Hasil dan Pembahasan}

\section{1 Data Pengujian}

Hasil data pengujian prestasi mesin dengan menggunakan bahan bakar pertamax $15 \mathrm{ml}$ adalah sebagai berikut:

Tabel 1 Data Prestasi Roller 7 gram

\begin{tabular}{cccc}
\hline No & Rpm & $\begin{array}{c}\text { Waktu } \\
\text { (Detik) }\end{array}$ & $\begin{array}{c}\text { Torsi } \\
\text { (Nm) }\end{array}$ \\
\hline 1 & 3000 & 72 & 0,4 \\
2 & 4000 & 71 & 0,75 \\
3 & 5000 & 67 & 0,9 \\
4 & 6000 & 44 & 2,29 \\
5 & 7000 & 39 & 2,72 \\
\hline
\end{tabular}

Tabel 2 Data Prestasi Roller 10,5 gram

\begin{tabular}{cccc}
\hline No & Rpm & $\begin{array}{c}\text { Waktu } \\
\text { (Detik) }\end{array}$ & $\begin{array}{c}\text { Torsi } \\
\text { (Nm) }\end{array}$ \\
\hline 1 & 3000 & 100 & 1,23 \\
2 & 4000 & 62 & 1 \\
3 & 5000 & 54 & 0,67 \\
4 & 6000 & 38 & 2,8 \\
5 & 7000 & 32 & 2 \\
\hline
\end{tabular}

Tabel 3 Data Prestasi Roller 13 gram

\begin{tabular}{cccc}
\hline No & Rpm & $\begin{array}{c}\text { Waktu } \\
\text { (Detik) }\end{array}$ & $\begin{array}{c}\text { Torsi } \\
\text { (Nm) }\end{array}$ \\
\hline 1 & 3000 & 91 & 0,4 \\
2 & 4000 & 48 & 0,9 \\
3 & 5000 & 56 & 1,2 \\
4 & 6000 & 32 & 0,9 \\
5 & 7000 & 23 & 3.2 \\
\hline
\end{tabular}

Dari tabel 1,2 dan 3 dapat dilihat laju penggunaan bahan bakar (detik) dan torsi (N.M). Terlihat perbedaan data yang diperoleh dalam pengujian mesin dengan menggunakan roler yang memiliki berat yang berbeda-beda. Data tersebut menunjukkan adanya pengaruh berat roleh pada CVT terhadap performa mesin.

\subsection{Analisa Data}


Data yang hasil pengujian akan digunakan untuk menghitung variabel daya, laju aliran bahan bakar spesifik serta prestasi mesin.
Berikut adalah tabel data hasil perhitungan prestasi mesin yang dihasilkan dengan menggunakan roler $7 \mathrm{gr}, 10.5 \mathrm{gr}$ dan $13 \mathrm{gr}$

Tabel 4: Perhitungan Data Roller 7 gram

\begin{tabular}{ccccccccc}
\multicolumn{10}{c}{ Tabel 4: Perhitungan Data Roller 7 gram } \\
\hline \multirow{2}{*}{ No } & rpm & $\begin{array}{c}\mathrm{t} \\
(\mathrm{detik})\end{array}$ & $\begin{array}{c}\mathrm{T} \\
(\mathrm{Nm})\end{array}$ & $\begin{array}{c}\mathrm{P} \\
(\mathrm{kW})\end{array}$ & $\begin{array}{c}\mathrm{m}_{\mathrm{f}} \\
(\mathrm{kg} / \mathrm{h})\end{array}$ & $\begin{array}{c}\mathrm{BSFC} \\
(\mathrm{kg} / \mathrm{kWh})\end{array}$ & $\begin{array}{c}\mathrm{Q}_{\text {in }} \\
(\mathrm{kW} / \mathrm{s})\end{array}$ & $\begin{array}{c}\eta_{\mathrm{th}} \\
(\%)\end{array}$ \\
\hline 1 & 3000 & 72 & 0,4 & 0,126 & 0,578 & 4,605 & 7,20 & $1,75 \%$ \\
2 & 4000 & 71 & 0,75 & 0,314 & 0,587 & 1,868 & 7,30 & $4,30 \%$ \\
3 & 5000 & 67 & 0,9 & 0,471 & 0,622 & 1,320 & 7,73 & $6,09 \%$ \\
4 & 6000 & 44 & 2,59 & 1,627 & 0,946 & 0,582 & 11,78 & $13,81 \%$ \\
5 & 7000 & 39 & 2,42 & 1,773 & 1,068 & 0,602 & 13,29 & $13,35 \%$ \\
\hline
\end{tabular}

Tabel 5 : Perhitungan Data Roller 10,5 gram

\begin{tabular}{ccccccrrr}
\hline No & $\mathrm{rpm}$ & $\begin{array}{c}\mathrm{t} \\
(\text { detik })\end{array}$ & $\begin{array}{c}\mathrm{T} \\
(\mathrm{Nm})\end{array}$ & $\begin{array}{c}\mathrm{P} \\
(\mathrm{kW})\end{array}$ & $\begin{array}{c}\mathrm{m}_{\mathrm{f}} \\
(\mathrm{kg} / \mathrm{h})\end{array}$ & $\begin{array}{c}\mathrm{BSFC} \\
\mathrm{kg} / \mathrm{kWh})\end{array}$ & $\begin{array}{c}\mathrm{Q}_{\text {in }} \\
(\mathrm{kW} / \mathrm{s})\end{array}$ & \multicolumn{1}{c}{$\begin{array}{c}\eta_{\mathrm{th}} \\
(\%)\end{array}$} \\
\hline 1 & 3000 & 100 & 0,5 & 0,157 & 0,416 & 2,653 & 5,18 & $3,03 \%$ \\
2 & 4000 & 62 & 1 & 0,419 & 0,672 & 1,604 & 8,36 & $5,01 \%$ \\
3 & 5000 & 54 & 1,67 & 0,874 & 0,771 & 0,882 & 9,60 & $9,11 \%$ \\
4 & 6000 & 38 & 2,8 & 1,758 & 1,096 & 0,623 & 13,64 & $12,90 \%$ \\
5 & 7000 & 32 & 2 & 1,465 & 1,301 & 0,888 & 16,19 & $9,05 \%$ \\
\hline
\end{tabular}

Tabel 6 :Perhitungan Data Roller 13 gram

\begin{tabular}{ccccccrrr}
\hline No & rpm & $\begin{array}{c}\mathrm{t} \\
(\text { detik })\end{array}$ & $\begin{array}{c}\mathrm{T} \\
(\mathrm{Nm})\end{array}$ & $\begin{array}{c}\mathrm{P} \\
(\mathrm{kW})\end{array}$ & $\begin{array}{c}\mathrm{m}_{\mathrm{f}} \\
(\mathrm{kg} / \mathrm{h})\end{array}$ & $\begin{array}{c}\mathrm{BSFC} \\
(\mathrm{kg} / \mathrm{kWh})\end{array}$ & $\begin{array}{c}\mathrm{Q}_{\text {in }} \\
(\mathrm{kW} / \mathrm{s})\end{array}$ & \multicolumn{1}{c}{$\begin{array}{c}\eta_{\text {th }} \\
(\%)\end{array}$} \\
\hline 1 & 3000 & 91 & 0,4 & 0,126 & 0,458 & 3,644 & 5,69 & $2,21 \%$ \\
2 & 4000 & 48 & 0,9 & 0,377 & 0,868 & 2,303 & 10,79 & $3,49 \%$ \\
3 & 5000 & 56 & 1,2 & 0,628 & 0,744 & 1,184 & 9,25 & $6,79 \%$ \\
4 & 6000 & 32 & 2,9 & 1,821 & 1,301 & 0,715 & 16,19 & $11,25 \%$ \\
5 & 7000 & 23 & 3,2 & 2,345 & 1,811 & 0,772 & 22,53 & $10,41 \%$ \\
\hline
\end{tabular}

\subsubsection{Torsi dan Daya Mesin}
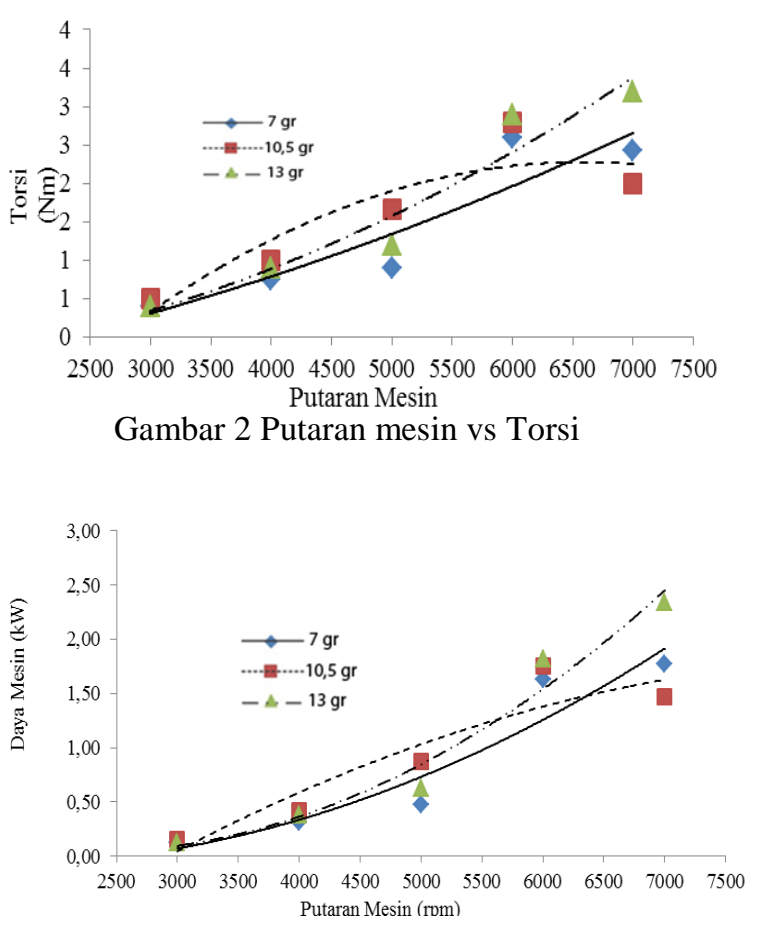

Gambar 2 Putaran mesin vs Daya Mesin
Gambar 2 dan 3 menunjukan grafik putaran mesin dengan torsi dan daya mesin. Pertambahan torsi dan daya terlihat seiring panambahan putaran mesin. Ini sesuai dengan karakter mesin pada umum nya. Grafik 2 dan 3 juga terrlihat bahwa Modifikasi berat roller pada penelitian ini dapat meningkatkan torsi dan daya pada mesin. Peningkatan yang paling tinggi pada putaran mesin $7000 \mathrm{rpm}$ adalah roller 13 gram dimana Torsi 3,2 (Nm) dan Daya $2,34 \quad(\mathrm{~kW})$ karena berat roller mempengaruhi gaya sentrifugal pada pulley primer sehingga semakin berat roller maka mesin pada putaran tinggi akan semakin kuat menjepit sabuk V belt, sehingga pada putaran tinggi untuk mentransfer torsi dan daya mesin ke roda belakang lebih besar 


\subsubsection{Brake Specifik Fuel Consumtion}

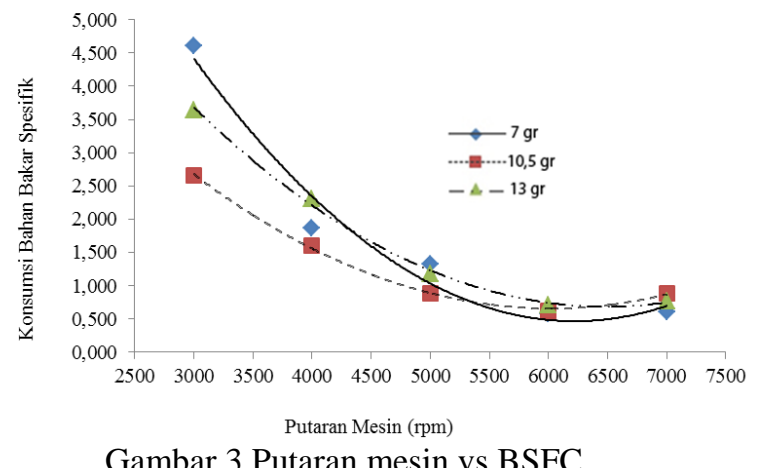

Gambar 3 juga dapat dilihat bahawa terjadi perbedaan laju penggunaan bahan bakar spesifik pada tiap-tiap jenis roler. Modifikasi berat roller juga dapat menghemat bahan bakar. Penghematan yang lebih besar terjadi pada roller 10,5 gram untuk putaran mesin rendah ke sedang. Pada putaran mesin tinggi penghematan bahan bakar lebih irit pada berat roller 7 gram karena semakin ringan roller maka beban yang dihasilan oleh mesin tidak berat pada bagian CVT.

\subsubsection{Efisiensi Termal}

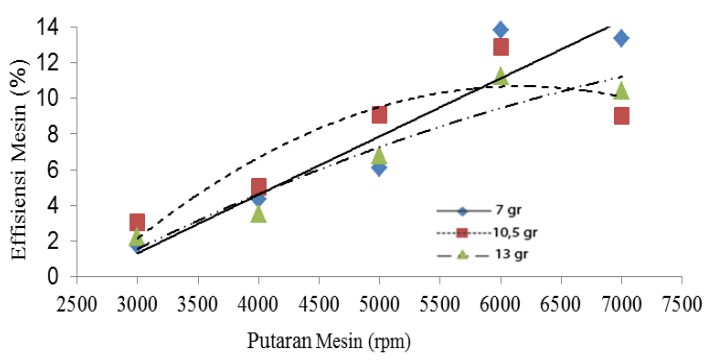

Gambar 4 Putaran mesin vs Efisiensi Termal

Modifikasi roller juga dapat meningkatkan efisiensi mesin pada berat 7 gram, efisiensi meningkat $13,81 \%$ pada putaran $6000 \mathrm{rpm}$ meski perubahan tidak signifikan akan tetapi roller yang lebih ringan dapat meningkatkan acceleration pada mesin

\section{KESIMPULAN}

Adapun kesimpulan yang dapat diperoleh dari pengujian ini adalah sebagai berikut:

1. Modifikasi berat roller pada penelitian ini dapat meningkatkan torsi dan daya pada mesin. Peningkatan yang paling tinggi pada putaran mesin $7000 \mathrm{rpm}$ adalah roller 13 gram dimana Torsi 3,2 $(\mathrm{Nm})$ dan Daya 2,34 $(\mathrm{kW})$

2. Penghematan yang lebih besar terjadi pada roller 10,5 gram untuk putaran mesin rendah ke sedang. Pada putaran mesin tinggi penghematan bahan bakar lebih irit pada berat roller 7 gram karena semakin ringan roller maka beban yang dihasilan oleh mesin tidak berat pada bagian CVT.

3. Efisiensi meningkat $13,81 \%$ pada putaran 6000 rpm meski perubahan tidak signifikan akan tetapi roller yang lebih ringan dapat meningkatkan acceleration pada mesin.

\section{DAFTAR PUSTAKA}

Ari Subagia dan Adi Atmika. (2009). Simulation Characteristics Continous Variable Transmission of Motor Cycle using Torque Control Based Fuzzy Logic. Iptek, The Journal for Technology and Science, Vol. 20, No. 1, February 2009.

Dr-Ing Mohamad Yamin dan Achmad Ardhiko W. (2011). Analisa dan Pengujian Roller pada Mesin Gokart Matic. Bekasi: UGD.

Lamtio Indo Fratomo. (2013). Cara Kerja dan Trouble Shooting CVT Suzuki Spin $125 R$. Semarang: UNNES.

Jama, Jalius, dkk. 2008. Teknik Sepeda Motor Jilid 1 untuk SMK Departemen Pendidikan Nasional: Jakarta

Salam, Rudi , 2009, PENGARUH PENGGUNAAN VARIASI BERAT ROLLER PADA SISTEM CVT (CONTINUOUSLY VARIABLE TRANSMISSION) TERHADAP PERFORMA SEPEDA MOTOR HONDA BEAT 110cc, Jurusan Teknik 
Mesin, Fakultas Teknik Universitas Islam Malang.

Kurniawan Khafid,Mochammad, Pengujian Transmisi Otomatis Cvt Mesin Sepeda Motor Suzuki Skydrive Tahun 2010 D3 Teknik Mesin, Fakultas Teknik Universitas Negeri Surabaya

Arismunandar, Wiranto. 1977. Penggerak Mula: Motor Bakar Torak. Bandung: Penerbit ITB.

Handayani, Sri Utami. 2007. Pemanfaatan Bio Ethanol Sebagai Bahan Bakar Pengganti Bensin.Gema Teknologi. Vol. 15. No. 2. Hal 99-102.

Muchammad. 2010. Analisa Energi Campuran Bioetanol Premium. ROTASI. Vol.12. No. 2. Hal 31-33.

Nofendri, Y., 2018. PENGARUH PENAMBAHAN ADITIF ETANOL PADA BENSIN RON 88 DAN RON 92 TERHADAP PRESTASI MESIN. Jurnal Konversi Energi dan Manufaktur UNJ, 5(1), pp.33-39.
Nofendri, Y., 2016. Efek Penambahan Aditif Oksigenat Kedalam Bahan Bakar Diesel pada Prestasi Mesin. Jurnal Kajian Teknik Mesin, 1(2), pp.94-103.

Raharjo, Winarno Dwi dan Karnowo. 2008. Mesin Konversi Energi.Semarang: Universitas Negeri Semarang Press.

Sarjono dan F. E. A. Putra. 2013. Studi Eksperimen Pengaruh Campuran Bahan Bakar Premium dengan Bioetanol Nira Siwalan terhadap Performa Motor 4 Langkah. Majalah Ilmiah STTR Cepu. No. 16. Hal. 1-11.

Supraptono. 2004. Bahan Bakar dan Pelumasan.Buku Ajar. Semarang: Jurusan Teknik Mesin Fakultas Teknik Universitas Negeri Semarang.

Wiratmaja, I Gede. 2010. “Analisa Unjuk Kerja Motor Bensin Akibat Pemakaian Biogasoline". Jurnal Ilmiah Teknik Mesin CakraM, Vol. 4. No.1. Hal 1625. 